\title{
Psychopathic personality traits in 5 year old twins: the importance of genetic and shared environmental influences
}

\author{
Catherine Tuvblad ${ }^{1,2} \cdot$ Kostas A. Fanti $^{3} \cdot$ Henrik Andershed $^{1} \cdot$ Olivier F. Colins $^{1,4}$. \\ Henrik Larsson ${ }^{5,6,7}$
}

Received: 28 April 2016 / Accepted: 21 August 2016 / Published online: 28 September 2016

(c) The Author(s) 2016. This article is published with open access at Springerlink.com

\begin{abstract}
There is limited research on the genetic and environmental bases of psychopathic personality traits in children. In this study, psychopathic personality traits were assessed in a total of 1189 5-year-old boys and girls drawn from the Preschool Twin Study in Sweden. Psychopathic personality traits were assessed with the Child Problematic Traits Inventory, a teacher-report measure of psychopathic personality traits in children ranging from 3 to 12 years old. Univariate results showed that genetic influences accounted for 57,25 , and $74 \%$ of the variance in the grandiose-deceitful, callous-unemotional, and impulsive-need for stimulation dimensions, while the shared environment accounted for 17, 48 and $9 \%$ (n.s.) in grandiose-deceitful and callous-unemotional, impulsive-need for stimulation dimensions, respectively. No sex differences were found in the genetic and environmental variance components. The non-shared environment accounted for the remaining 26,27 and $17 \%$ of the variance, respectively. The three dimensions of psychopathic personality were moderately
\end{abstract}

Catherine Tuvblad

Tuvblad@usc.edu; Catherine.Tuvblad@oru.se

Kostas A. Fanti

kfanti@ucy.ac.cy

Henrik Andershed

Henrik.Andershed@oru.se

Olivier F. Colins

o.colins@curium.nl

Henrik Larsson

henrik.larsson@ki.se

1 School of Psychology, Law and Social Work, Örebro University, Örebro, Sweden

2 Department of Psychology, University of Southern

California, Los Angeles, CA, USA correlated (0.54-0.66) and these correlations were primarily mediated by genetic and shared environmental factors. In contrast to research conducted with adolescent and adult twins, we found that both genetic and shared environmental factors influenced psychopathic personality traits in early childhood. These findings indicate that etiological models of psychopathic personality traits would benefit by taking developmental stages and processes into consideration.

Keywords Psychopathic personality traits · Heritability · Teacher ratings $\cdot$ Childhood

\section{Introduction}

Psychopathy is a multifaceted syndrome often described as a constellation of affective (e.g., lack of remorse or guilt, shallow affect, callous/lack of empathy), interpersonal

3 Department of Psychology, University of Cyprus, Nicosia, Cyprus

4 Departments of Child and Adolescent Psychiatry, CuriumLeiden University Medical Center, Leiden, The Netherlands

5 Department of Medical Epidemiology and Biostatistics, Karolinska Institute, Solna, Sweden

6 Karolinska Institute Center for Neurodevelopmental Disorders, Solna, Sweden

7 School of Medical Sciences, Örebro University, Örebro, Sweden 
(e.g., glib/superficial charm, grandiose self-worth, manipulative), behavioral and antisocial (e.g., poor behavior control, impulsive, inability to accept responsibility for one's actions) features $[17,38]$. Psychopathy is related to a range of negative and dysfunctional outcomes including substance use, criminal behavior, psychopathology (e.g., borderline personality disorder) $[21,40,42,44,56]$, and social maladjustment such as lower educational performance, unemployment and poor social relationships $[4,19,44$, 71]. The prevalence of psychopathy has been estimated to be between 0.6 and $4 \%$ in the general population, with a higher proportion of males to females $[65,75]$. Despite the low prevalence, these individuals are believed to account for a large portion of all serious crimes and their recidivism rate is higher than for other offenders $[8,38,56]$. Furthermore, psychopathy is considered to be a neurodevelopmental disorder rooted early in life [22, 33, 35, 36, 41, 52]. Identifying individuals with psychopathic personality traits early in development is, therefore, crucial for intervention efforts, especially since these traits have been linked to early engagement in criminal activities (e.g., [39, 58, 62]). To date, there has been very limited research on the genetic and environmental etiology of psychopathic personality traits in young children. This study aimed to bridge this research gap by investigating the extent of genetic influences on these traits in boys and girls and to investigate whether shared environmental influences also play a significant role.

Recent twin studies report that heritable factors have a moderate to high influence, non-shared environmental factors have a small to moderate influence, and shared environmental factors have little or no importance explaining the variance in psychopathic personality (for reviews: [66, 72]). This has been found among adolescents (e.g., [5, 9, $25,30,47,48,64,69,70]$ ), as well as among adults (e.g., $[5,10,11,44])$. However, a more mixed pattern has been found across the few studies that have included children (i.e., participants 12 years of age or younger; see Table 1 for a summary). Please also note that the majority of the studies summarized in Table 1 have only examined the affective (or callous-unemotional) traits. For example, an early study by Viding et al. [76] using DeFries-Fulker extreme analysis showed that the heritability of callousunemotional traits was $67 \%$ in a sample of 7-year-old twins. Furthermore, Bezdjian et al. used the Child Psychopathy Scale [51] to assess psychopathic personality traits in a set of 9-10 year old twins. The affective-interpersonal factor was primarily influenced by genetic factors with slight sex differences (boys $64 \%$; girls $49 \%$ ), with the non-shared environment contributing $36 \%$ in boys and $44 \%$ in girls. Similarly, the impulsive-antisocial factor was primarily influenced by genetic factors (boys $46 \%$; girls $58 \%$ ), with the non-shared environment contributing
$53 \%$ in boys and $37 \%$ in girls. There were little and nonsignificant influence from the shared environment [6]. Ficks et al. included children as young as 4 years in their study (age range 4.4-17.8 years, age-corrected analysis) and the antisocial process screening device [31] was used to assess psychopathic personality traits. For callous-unemotional traits, genetic influences explained $49 \%$ of the variance, shared environment $19 \%$ and the non-shared environment $32 \%$; for narcissism, genetic influences explained $63 \%$ and the non-shared environment $37 \%$; and for impulsivity, additive and non-additive genetic influences contributed $61 \%$ in boys and $74 \%$ in girls, with the non-shared environment contributing the remaining variance.

In sum, studies examining the genetic and environmental etiology of psychopathic personality traits in young children are scarce. The few studies that do exist have produced diverse findings showing a moderate to strong heritability; the role of the shared environment on these traits is mixed, and whether or not the genetic and environmental estimates vary across sex is unclear. Using data from a population-based sample of Swedish 5-year-old twins this study had the following goals: (1) to examine the genetic and environmental etiology of the three psychopathic personality dimensions-grandiose-deceitful, a callous-unemotional, and impulsive-need for stimulation-assessed with the Child Problematic Traits Inventory (CPTI; [13]), which was designed to be used specifically among young children; (2) to examine whether the genetic and environmental etiology of the three psychopathic personality dimensions is comparable in boys and girls; and (3) to examine how much of the phenotypic correlation among these dimensions that are accounted for by genetic and environmental influences.

\section{Method}

\section{Participants and procedure}

This study used data from the Preschool Twin Study in Sweden (PETSS) project. The overall aim of PETSS was to examine how genetic and environmental factors in early childhood contribute to cognition, emotional regulation and behavioral problems. Parents of all twins born in Sweden between January, 2004 and May, 2005 were identified through the Swedish population-based medical birth register and contacted 1 month prior to their twins' 5th birthday. Thus, all children in PETSS were 5 years old at study start. Questionnaires were mailed to parents and pre-school teachers of 1261 twin pairs $(n=2522$ children). Nonresponders were approached with up to three reminders. Parents were approached separately, resulting in $828(65 \%)$ 


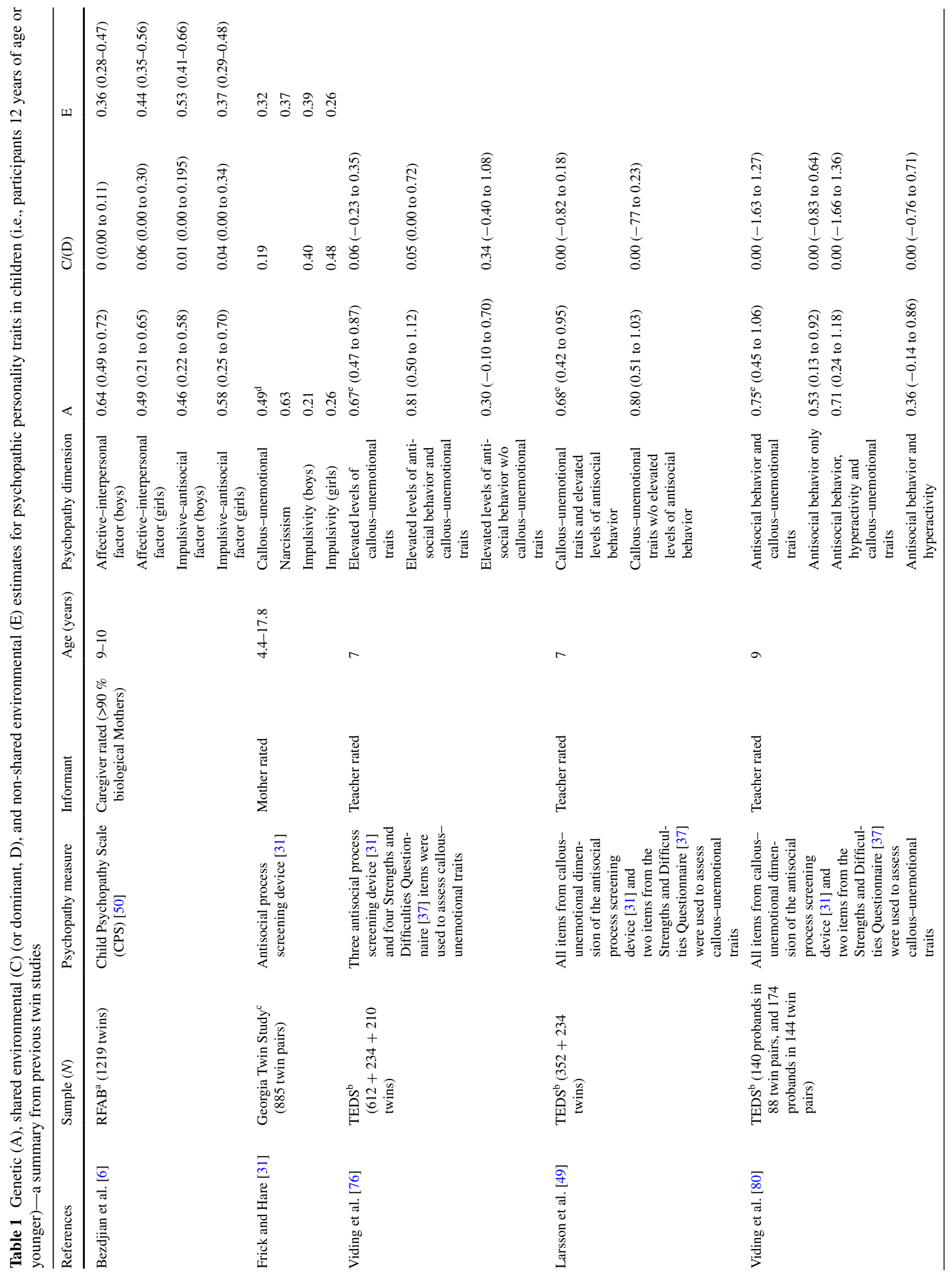




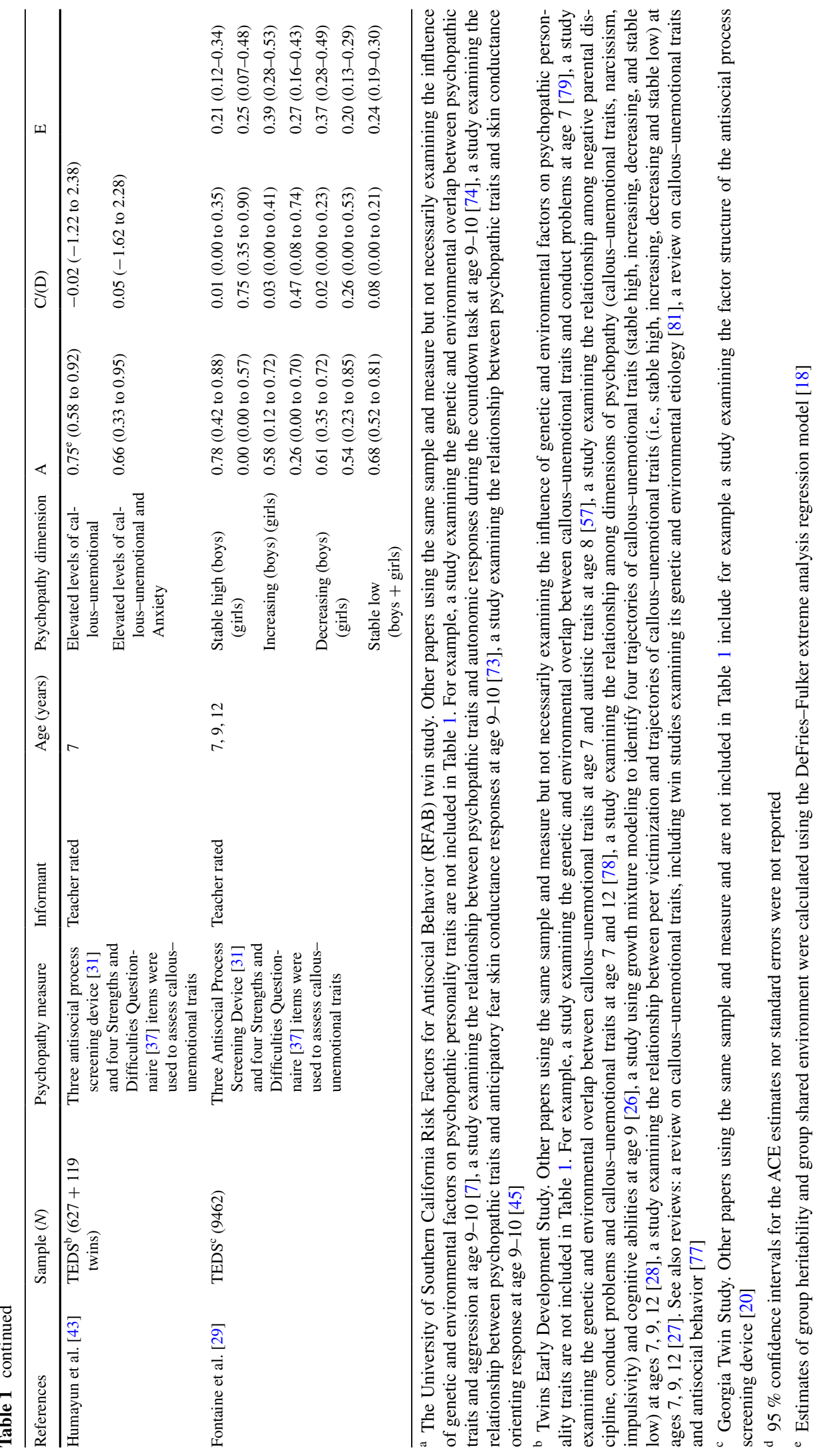


Table 2 Descriptive statistics and twin correlations for the psychopathic personality dimensions grandiose-deceitful, callous-unemotional and impulsive-need for stimulation at age 5, teacher ratings

\begin{tabular}{|c|c|c|c|c|c|}
\hline \multirow[b]{2}{*}{ Grandiose-deceitful (mean, SD) } & \multicolumn{2}{|r|}{ Boys } & \multicolumn{3}{|l|}{ Girls } \\
\hline & & $1.41,0.52 n=591$ & $1.33,0.49 n=598$ & & $=0.0025$ \\
\hline Callous-unemotional (mean, SD) & & $1.60,0.65 n=591$ & $1.38,0.51 n=598$ & & 0.001 \\
\hline \multirow[t]{2}{*}{ Impulsive-need for stimulation (mean, SD) } & & $2.11,0.72 n=591$ & $1.91,0.66 n=598$ & & 0.001 \\
\hline & MZ & $\mathrm{DZ}$ & $\mathrm{MZ}$ & $\mathrm{DZ}$ & $\overline{\text { OSDZ }}$ \\
\hline Grandiose-deceitful & $0.79 *$ & $0.25^{*}$ & $0.75 *$ & $0.44 *$ & $0.50^{*}$ \\
\hline Callous-unemotional & $0.72 *$ & $0.66^{*}$ & $0.66^{*}$ & $0.58^{*}$ & $0.54 *$ \\
\hline Impulsive-need for stimulation & $0.82 *$ & $0.25 *$ & $0.80 *$ & $0.34 *$ & $0.54 *$ \\
\hline
\end{tabular}

$M Z$ monozygotic, $D Z$ dizygotic, $O S D Z$ opposite sex

$* p<0.05$, transformed data

responses from the mothers, and $698(55 \%)$ responses from the fathers. Mother and/or father ratings were available from 879 twin pairs ( $n=1758$ children). The teacher-rated questionnaires had a response rate of $54 \% 686$ twin pairs ( $n=1372$ children). The PETSS project was evaluated and approved by an ethics committee at the Karolinska Institute (\#2007-1034). For more information on study protocol and procedures: http://ki.se/meb/petss, and [12].

The main focus of this study was to examine genetic and environmental influences on psychopathic personality traits assessed with the CPTI [13]. The CPTI was completed only by teachers and data were available from a total of $n=1189$ children (591 boys; 598 girls), Table 2.

Typically in Sweden, children start pre-school (day care) around or soon after their first birthday. They remain in preschool for a period of approximately 4 years. They go to Kindergarten in the fall of the year that they turn 6 years. The PETSS questionnaire was mailed out and completed by participating pre-school teachers close to the twins' fifth birthday. Of the participating teachers, $3 \%$ reported that they had known the twins less than 6 months, $12 \%$ reported that they had known the twins between 6 and 12 months, $11 \%$ reported that they had known the twins between 13 and 18 months, $12 \%$ reported that they had known the twins between 19 and 24 months, and $62 \%$ reported that they had known the twins more than 24 months.

\section{Measures}

Psychopathic personality traits were assessed with the Child Problematic Traits Inventory (CPTI) [13, 14, 16, 63]. The CPTI has the following response format: $1=$ 'Does not apply at all'; 2 = 'Does not apply well'; 3 = 'Applies fairly well'; and 4 = 'Applies very well'. Respondents were instructed to rate each child on how he/she usually and typically behaves rather than based on how he or she behaves at the moment. CPTI contains 28 items which have been found to load on three factors, and this three factor structure has been identified in PETSS across boys and girls [15], as well as in another Swedish sample across boys and girls and across age [13]. The grandiosedeceitful factor score includes eight items (e.g., lies often to avoid problems; seems to see himself/herself as superior compared to others), the callous-unemotional factor score includes 10 items (e.g., seldom expresses sympathy for others; usually does not seem to share others' joy and sorrow), and the impulsive-need for stimulation factor score includes ten-items (e.g., likes change and that things happen all the time; often has difficulties with awaiting his/her turn). The CPTI three factor scores showed excellent internal consistency (all Cronbach's alphas in the present study $>0.89$ ). In terms of external validity, the three factors exhibited positive and significant correlations with teacher and parent rated variables of interest in PETSS, including conduct problems, attention-deficit/hyperactivity (ADHD) symptoms, aggression, and fearlessness [15]. All three scores were log-transformed to approximate a normal distribution.

\section{Statistical analyses}

\section{Descriptive statistics and correlations}

Descriptive statistics, including means and standard deviations, were first computed for three psychopathic personality dimensions: grandiose-deceitful, callous-unemotional, and impulsive-need for stimulation, as well as their phenotypic correlations.

\section{Twin modeling}

In the twin design, data from monozygotic (MZ) and dizygotic (DZ) twins are used to decompose the variance in a measured trait to genetic and environmental components. MZ twins share their common environment and they are assumed to share $100 \%$ of their genes. DZ twins also share their common environment and they are assumed to share 
about $50 \%$ of their genes. By comparing the resemblance between $\mathrm{MZ}$ and $\mathrm{DZ}$ twins, the variance of a measured trait can be divided into additive genetic factors (A), shared environmental factors $(\mathrm{C})$, and non-shared environmental factors (E). Shared environmental factors refer to non-genetic influences that contribute to similarity within pairs of twins, whereas non-shared environmental factors refer to experiences that make siblings dissimilar [55].

To get a first indication of the underlying sources of variance in grandiose-deceitful, callous-unemotional, and impulsive-need for stimulation dimensions, comparisons were made among twin correlations (Twin-1-Twin-2 correlations). A DZ correlation approximately half the value of the MZ correlation would indicate the presence of additive genetic effects, whereas a DZ correlation more than half an MZ correlation indicates the presence of both genetic and shared environmental effects [55].

\section{Univariate modeling}

Univariate models were fit to grandiose-deceitful, callous-unemotional, and impulsive-need for stimulation separately to estimate the relative contributions of genetic factors (A), shared environmental factors (C), and nonshared environmental factors (E, plus error). To test for sex differences in the variance components, a model in which the genetic and environmental effects were allowed to differ between boys and girls were compared against a model in which the estimates were constrained to be equal. A saturated model, which estimates the variances, covariances, and means were first fit and used as a baseline model to which all subsequent models were compared.

\section{Bivariate modeling}

A bivariate Cholesky decomposition was fit to estimate how much of the phenotypic correlation that is due to genetic and environmental influences between grandiosedeceitful, callous-unemotional and impulsive-need for stimulation, also referred to as bivariate heritability, bivariate shared environment and bivariate non-shared environment. These estimates are proportions and range from 0 to 1. They provide information regarding the extent to which the phenotypic correlation between two traits is mediated by genetic and/or environmental factors.

All genetic models were fit with the structural equation program Mx [54]. The goodness of fit was compared through the difference in the Chi-square statistic $\left(\chi^{2}\right)$, where a significant $\chi^{2}$ indicates that the model with less number of parameters fits the data worse. Akaike Information Criterion (AIC) [1] and Bayesian Information Criterion (BIC) [60] were also used to determine fit, where increasingly negative values correspond to increasingly better fitting models.

\section{Results}

\section{Descriptive statistics and correlations}

There were significant mean differences between boys and girls, with boys having higher mean values for grandiose-deceitful, callous-unemotional, and impulsive-need for stimulation. The pattern of the twin correlations indicates that genetic and shared environmental influences are important for the three psychopathic personality dimensions, Table 2.

\section{Univariate genetic analysis}

Univariate model-fitting results for grandiose-deceitful, callous-unemotional, and impulsive-need for stimulation are displayed in Table 3. A low DZ twin correlation (in boys for grandiose-deceitful; boys and girls for impulsiveneed for stimulation, Table 2) may be due to non-additive genetic effects, such as epistasis or dominance [54]. A model estimating additive genetic (A) effects, non-additive genetic (D) effects and non-shared environmental (E) effects was, therefore, first tested. However, the full ACE model (Model 2 in Table 3) was found to fit better than the ADE model (grandiose-deceitful: AIC 768.632, BIC -2210.855; impulsive-need for stimulation: AIC 694.695, BIC -2247.824).

The full ACE model described the data better than the baseline saturated model (Model 2, grandiose-deceitful: $\chi^{2}=7.081, d f=9, p=0.629$, callous-unemotional: $\chi^{2}=5.093, d f=9, p=0.826$, impulsive-need for stimulation: $\left.\chi^{2}=14.242, d f=9, p=0.114\right)$; Model 2 also had smaller AIC and BIC. A model constraining genetic and environmental components to be equal in boys and girls provided a better fit than the full ACE model (Model 3, grandiose-deceitful: $\chi^{2}=3.962, d f=3, p=0.266$, callousunemotional: $\chi^{2}=4.29, d f=3, p=0.232$, impulsive-need for stimulation: $\left.\chi^{2}=1.234, d f=3, p=0.745\right)$. Genetic influences accounted for 57,25 , and $74 \%$ of the phenotypic variance for grandiose-deceitful, callous-unemotional and impulsive-need for stimulation, respectively; shared environmental factors accounted for 17,48 , and $9 \%$ (n.s.), and nonshared environmental factors (including error) accounted for the remaining variance, 26,27 , and $17 \%$, respectively.

\section{Bivariate genetic analysis}

A bivariate Cholesky decomposition was next fit to data. The Cholesky decomposition fit the data better than a saturated model $\left(\chi^{2}=76.143, d f=69, p=0.260\right)$. Similar to the univariate analyses, the genetic and environmental variance components could be constrained to be equal in boys and girls $\left(\chi^{2}=21.157, d f=18, p=0.272\right)$. The 
Table 3 Univariate genetic results and parameter estimates for the psychopathic personality dimensions grandiose-deceitful, callous-unemotional and impulsive-need for stimulation at age 5, teacher ratings

\begin{tabular}{|c|c|c|c|c|c|c|c|c|c|c|}
\hline \multirow[t]{2}{*}{ Model \# } & \multicolumn{7}{|l|}{ Overall fit } & \multicolumn{3}{|l|}{ Parameter estimates } \\
\hline & $-2 \log$ & $d f$ & AIC & $\mathrm{BIC}$ & $\chi^{2}$-diff & $\Delta d f$ & $p$ & $\mathrm{~A}$ & $\mathrm{C}$ & $\mathrm{E}$ \\
\hline \multicolumn{11}{|l|}{ Grandiose-deceitful } \\
\hline 1. Saturated model & 3109.314 & 1172 & 765.314 & -2194.920 & & & & & & \\
\hline $\begin{array}{l}\text { 2. ACE } \\
\text { boys } \neq \text { girls }\end{array}$ & 3116.395 & 1181 & 754.395 & -2220.173 & 7.081 & 9 & 0.629 & & & \\
\hline $\begin{array}{l}\text { 3. ACE } \\
\text { boys = girls }\end{array}$ & 3120.357 & 1184 & 752.357 & -2227.789 & 11.043 & 12 & 0.525 & $0.57(0.39-0.75)$ & $0.17(0.001-0.32)$ & $0.26(0.21-0.33)$ \\
\hline \multicolumn{11}{|l|}{ Callous-unemotional } \\
\hline 1. Saturated model & 3018.635 & 1172 & 674.635 & -2240.259 & & & & & & \\
\hline $\begin{array}{l}\text { 2. ACE } \\
\text { boys } \neq \text { girls }\end{array}$ & 3023.728 & 1181 & 661.728 & -2266.506 & 5.093 & 9 & 0.826 & & & \\
\hline $\begin{array}{l}\text { 3. ACE } \\
\text { boys }=\text { girls }\end{array}$ & 3028.018 & 1184 & 660.018 & -2273.959 & 9.383 & 12 & 0.670 & $0.25(0.10-0.40)$ & $0.48(0.35-0.60)$ & $0.27(0.22-0.33)$ \\
\hline \multicolumn{11}{|c|}{ Impulsive-need for stimulation } \\
\hline 1. Saturated model & 3035.396 & 1172 & 691.396 & -2231.879 & & & & & & \\
\hline $\begin{array}{l}\text { 2. ACE } \\
\text { boys } \neq \text { girls }\end{array}$ & 3049.638 & 1181 & 687.638 & -2253.552 & 14.242 & 9 & 0.114 & & & \\
\hline $\begin{array}{l}\text { 3. ACE } \\
\text { boys = girls }\end{array}$ & 3050.872 & 1184 & 682.872 & -2262.532 & 15.476 & 12 & 0.216 & $0.74(0.59-0.86)$ & $0.09(0.00-0.23)$ & $0.17(0.14-0.21)$ \\
\hline
\end{tabular}

AIC Akaike's Information Criterion, BIC Bayesian Information Criterion, $\chi^{2}$-diff difference in log-likelihoods between models, $d f$ degrees of freedom, $A$ additive genetic, $C$ shared environment, $E$ non-shared environment

Table 4 Proportion of the phenotypic correlations between grandiose-deceitful, callous-unemotional, and impulsive-need for stimulation accounted for by genetic (A), shared environmental (C) and non-shared environmental (E) factors

\begin{tabular}{lllll}
\hline & Phenotypic correlation & bivh $^{2}(95 \%$ CI $)$ & bivc $^{2}(95 \%$ CI $)$ & bive $^{2}(95 \%$ CI $)$ \\
\hline Grandiose-deceitful/callous-unemotional & 0.66 & $0.25(0.05-0.43)$ & $0.52(0.36-0.67)$ & $0.23(0.17-0.32)$ \\
Grandiose-deceitful/impulsive-need for stimulation & 0.61 & $0.56(0.40-0.72)$ & $0.26(0.12-0.40)$ & $0.18(0.12-0.24)$ \\
Callous-unemotional/impulsive-need for stimulation & 0.54 & $0.39(0.20-0.59)$ & $0.44(0.26-0.60)$ & $0.17(0.11-0.24)$ \\
\hline
\end{tabular}

$b i v h^{2}$ bivariate heritability, $b i v c^{2}$ bivariate shared environment, bive ${ }^{2}$ bivariate non-shared environment

phenotypic correlations were moderate to high across the three psychopathic personality dimensions (Table 3). The phenotypic correlations between grandiose-deceitful, callous-unemotional, and impulsive-need for stimulation were primarily accounted for by genetic and shared environmental influences (Table 4).

\section{Discussion}

This study aimed to investigate the genetic and environmental sources among three psychopathic personality dimensions, grandiose-deceitful, callous-unemotional and impulsive-need for stimulation in a community sample of 5-year-old children assessed by teachers. There are three main points of interest for discussion in this study. First, familial influences (i.e., genetic and/or shared environment) explained the majority of variance in grandiose-deceitful, callous-unemotional and impulsive-need for stimulation. Second, no sex differences were found in the genetic and environmental variance components. Third, the proportions of the phenotypic correlations among these dimensions were mainly mediated by genetic and shared environmental influences.

Similar to Ficks et al. [25], our univariate analyses indicated that genetic and shared environmental influences primarily explained the variance in the callous-unemotional dimension, and that a large genetic influence was important for impulsive-need for stimulation. We also found that genetic and shared environmental influences explained the variances in grandiose-deceitful, whereas Ficks et al. found that mainly genetic influences were important for 
narcissism. This discrepancy in findings between our study and Ficks et al. could partly be explained by methodological differences in that we were using the CPTI rated by teachers and they were using the antisocial process screening device rated by mothers. As genetic influences on psychopathic personality traits may vary across the ways in which these traits are measured, in terms of both informant and instrument used [69], more research examining the genetic and environmental etiology of these traits in early childhood is warranted. Also, Ficks et al. [25] agecorrected their data (age range 4.4-17.8 years), whereas we used a sample of 5-year-old twins.

Further, callous-unemotional traits have previously received attention $[25,32,41]$, and recently a callous-unemotional-based specifier for the diagnosis of conduct disorder has been added in the fifth edition of the diagnostic and statistical manual of mental disorders [2]. Our finding of a moderate genetic (25\%) influence and higher shared environmental (48 \%) influence on the callous-unemotional dimension is in sharp contrast to findings by Viding et al. [76] who found a high heritability $(67 \%)$ for antisocial behavior in the presence of callous-unemotional traits as reported by teachers in a sample of 7 year old twins, and no influence from the shared environment. Thus, we found that both genetic and shared environmental factors contributed to callous-unemotional traits at age five. Shared environmental risk factors may include family related factors (e.g., neglect, prenatal stressors) or contextual factors in the surrounding community $[53,68]$. Our finding agree with prior work linking environmental factors to callousunemotional traits and studies suggesting that interventions focusing on environmental stimuli may be effective in reducing callous-unemotional traits (for a review: [34]). The moderate genetic influence in our sample for callousunemotional traits might also be related to heterogeneity within these traits, with subgroups showing differences in behavioral and physiological measures of anxiety and fear reactivity (e.g., [23, 24]).

The three dimensions grandiose-deceitful, callous-unemotional and impulsive-need for stimulation were all moderately correlated. The proportions of these phenotypic correlations were mainly accounted for by genetic and shared environmental influences. Again, these findings provide support for the importance of both genetic and shared environmental influences in psychopathic personality traits in young children.

The significant shared environmental influences in particular for callous-unemotional traits identified in our sample of 5-year-old twins are of great importance. Typically, a pattern of decreasing shared environment and a concomitant increase in heritability over the course of development is found; this has been reported for several phenotypes including personality traits, cognitive abilities, and aggression [59]. It will be interesting to follow the twins included in this study across development to see if a similar pattern will emerge for the shared environment on psychopathic personality traits. Then again, the bulk of literature on psychopathy has shown little or no influence of the shared environment (e.g., [66, 72]); however, the majority of previous research has been conducted on adolescent or adult twin samples. Of note, twin studies typically have low power to detect shared environmental influences relative to genetic influences. Shared environmental influences can also be confounded with for example the effects of assortative mating or passive gene-environment correlation $(r G E)$ [46]. Thus, part of the shared environment we found could be explained by the fact that the same teacher was rating both twins in a pair [3]. In our case, $97 \%$ of the participating twin pairs went to the same pre-school class, and $85 \%$ were rated by the same teacher. Studies of children typically rely on parent or teacher reports; it is, therefore, possible that the shared environment found in these studies and in our study is partly an artifact of rater bias. This suggests that future studies are needed examining how genetic and environmental factors influence psychopathic personality traits in children, and it will be interesting to see if they can replicate our finding of a shared environmental component.

We also found higher mean values for psychopathic personality traits in boys than girls across all three psychopathic personality dimensions, indicating that these traits are somewhat more prevalent among boys than girls. Higher mean values for psychopathic personality traits have also been found among males than females across incarcerated and community samples [75]. However, no differences in the magnitude in genetic and environmental variance components were found across boys and girls and the variance components could be constrained to be equal. This finding is in contrast to Bezdjian et al. [7], who found significant sex differences across 9-10 year old boys and girls, with the affective-interpersonal factor showing higher heritability in boys and the impulsive-antisocial factor showing higher heritability in girls. Similarly, Ficks et al. [25] found sex differences in the Impulsivity dimension, with a higher heritability in girls. Our findings suggest that despite sex differences on a mean level, the underlying genetic and environmental etiology of these traits appears to be similar for both boys and girls. This would in turn indicate that there are specific circumstances (biological) or experiences (social, environmental) that may lead to greater expression of psychopathic personality traits in boys. Future research needs to determine which specific factors that contributes to the sex difference in prevalence.

\section{Limitations}

A few limitations in this study must be considered when interpreting these findings. First, we examined the genetic 
and environmental influences on psychopathic personality traits in a community sample of young twins. Our results may not be generalizable to children in clinical settings. We only had one time point, future research need to investigate how genetic and environmental factors influence change in these traits from early childhood through adolescence and whether the shared environment that we found will decrease across development. There are several assumptions related to the classical twin design [59], for example, the heritability estimate is time and population specific. A more detailed discussion of these and other assumption in the twin design in relation to psychopathology can be found elsewhere [67].

\section{Conclusions}

In contrast to research conducted with adolescent and adult twins, we found that both genetic and shared environmental influences are of importance for psychopathy personality traits in childhood. The phenotypic correlations between three dimensions of psychopathic personality grandiosedeceitful, callous-unemotional, and impulsive-need for stimulation were primarily accounted for by common genetic and common shared environmental influences. This highlights the importance of considering all three dimensions of psychopathic personality simultaneously in clinical work as well as in future research, see also [13, 61]. These findings further indicate that etiological models of psychopathic personality should take developmental stages and processes into consideration. This evidence is important for prevention efforts, suggesting that preventions designed to reduce the development of psychopathic personality traits can be successful if administered during the preschool developmental period.

Acknowledgments We thank the twins, their families and teachers for their participation.

\section{Compliance with ethical standards}

Conflict of interest Henrik Larsson has served as a speaker for Eli Lilly and has received a research grant from Shire; both outside the submitted work. Author Catherine Tuvblad declares that she has no conflict of interest. Author Kostas A. Fanti declares that he has no conflict of interest. Author Henrik Andershed declares that he has no conflict of interest. Author Olivier F. Colins declares that he has no conflict of interest.

Funding We acknowledge financial support from the Swedish Research Council (2014-3831).

Ethical approval All procedures performed in studies involving human participants were in accordance with the ethical standards of the institutional and/or national research committee and with the 1964 Helsinki declaration and its later amendments or comparable ethical standards.
Informed consent Informed consent was obtained from all individual participants included in the study.

Open Access This article is distributed under the terms of the Creative Commons Attribution 4.0 International License (http://creativecommons.org/licenses/by/4.0/), which permits unrestricted use, distribution, and reproduction in any medium, provided you give appropriate credit to the original author(s) and the source, provide a link to the Creative Commons license, and indicate if changes were made.

\section{References}

1. Akaike AC (1987) Factor analysis and AIC. Psychometrika 52:317-332

2. American Psychiatric Association (2013) Diagnostic and statistical manual of mental disorders, vol 5. American Psychiatric Publishing, Arlington

3. Baker LA, Jacobson KC, Raine A, Lozano DI, Bezdjian S (2007) Genetic and environmental bases of childhood antisocial behavior: a multi-informant twin study. J Abnorm Psychol 116(2):219-235

4. Beaver KM, da Silva Costa C, Poersch AP, Freddi MC, Stelmach MC, Connolly EJ, Schwartz JA (2014) Psychopathic personality traits and their influence on parenting quality: results from a nationally representative sample of Americans. Psychiatr Q 85(4):497-511

5. Beaver, K. M., Vaughn, M. G., and Delisi, M. (2013). Nonshared environmental effects on adulthood psychopathic personality traits: results from a monozygotic twin difference scores analysis. Psychiatr Q (Epub ahead of print)

6. Bezdjian S, Raine A, Baker LA, Lynam D (2011) Psychopathic personality in children: genetic and environmental contribution. Psychol Med 41(3):589-600

7. Bezdjian S, Tuvblad C, Raine A, Baker LA (2011) The genetic and environmental covariation among psychopathic personality traits, and reactive and proactive aggression in childhood. Child Dev 82(4):1267-1281

8. Blair JR, Mitchell DA, Blair K (2007) The psychopath, emotion and the brain. Blackwell Publishing Ltd, Oxford

9. Blonigen DM, Hicks BM, Krueger RF, Patrick CJ, Iacono WG (2005) Psychopathic personality traits: heritability and genetic overlap with internalizing and externalizing psychopathology. Psychol Med 35:637-648

10. Blonigen DM, Hicks BM, Krueger RF, Patrick CJ, Iacono WG (2006) Continuity and change in psychopathic traits as measured via normal-range personality: a longitudinal-biometric study. J Abnorm Psychol 115(1):85-95

11. Brook M, Panizzon MS, Kosson DS, Sullivan EA, Lyons MJ, Franz CE, Kremen WS (2010) Psychopathic personality traits in middle-aged male twins: a behavior genetic investigation. J Personal Disord 24(4):473-486

12. Burt SA, Larsson H, Lichtenstein P, Klump KL (2012) Additional evidence against shared environmental contributions to attentiondeficit/hyperactivity problems. Behav Genet 42(5):711-721

13. Colins OF, Andershed H, Frogner L, Lopez-Romero L, Veen V, Andershed AK (2014) A new measure to assess psychopathic personality in children: the Child Problematic Traits Inventory. J Psychopathol Behav Assess 36(1):4-21

14. Colins OF, Fanti K, Larsson H, Anckarsäter H (2016) Psychopathic traits in early childhood: further validation of the Child Problematic Traits Inventory. Assessment:1-16 (epub ahead of print)

15. Colins OF, Kostas AF, Larsson H, Andershed H (2015) Psychopathic traits in early childhood: further validation of the Child Problematic Traits Inventory (in preparation) 
16. Colins OF, Veen V, Venstra M, Frogner L, Andershed H (2016) The Child Problematic Traits Inventory in a Dutch General Population sample of 3- to 7-year-old children. Eur J Psychol Assess. doi:10.1027/1015-5759/a000347

17. Cooke DJ, Michie C (2001) Refining the construct of psychopathy: towards a hierarchical model. Psychol Assess 13(2):171-188

18. DeFries JC, Fulker DF (1985) Multiple regression analysis of twin data. Behav Genet 15:467-473

19. DeLisi M, Vaughn M, Beaver KM, Wexler J, Barth AE, Fletcher JM (2011) Fledgling psychopathy in the classroom: ADHD subtypes, psychopathy, and reading comprehension in a community sample of adolescents. Youth Violence Juv Justice 9:43-58

20. Dong L, Wu H, Waldman ID (2014) Measurement and structural invariance of the antisocial process screening device. Psychol Assess 26(2):598-608

21. Douglas KS, Vincent GM, Edens JF (2006) Risk for criminal recidivism: the role of psychopathy. In: Patrick CJ (ed) Handbook of psychopathy. Guilford Press, New York, pp 533-554

22. Fairchild G, van Goozen SH, Calder AJ, Goodyer IM (2013) Research review: evaluating and reformulating the developmental taxonomic theory of antisocial behaviour. J Child Psychol Psychiatry 54(9):924-940

23. Fanti KA, Demetriou CA, Kimonis ER (2013) Variants of callous-unemotional conduct problems in a community sample of adolescents. J Youth Adolesc 42(7):964-979

24. Fanti KA, Panayiotou G, Lazarou C, Michael R, Georgiou G (2016) The better of two evils? Evidence that children exhibiting continuous conduct problems high or low on callous-unemotional traits score on opposite directions on physiological and behavioral measures of fear. Dev Psychopathol 28(1):185-198. doi:10.1017/S0954579415000371

25. Ficks CA, Dong L, Waldman ID (2014) Sex differences in the etiology of psychopathic traits in youth. J Abnorm Psychol 123(2):406-411

26. Fontaine N, Barker ED, Salekin RT, Viding E (2008) Dimensions of psychopathy and their relationships to cognitive functioning in children. J Clin Child Adolesc Psychol 37(3):690-696

27. Fontaine NM, Hanscombe KB, Berg MT, McCrory E, Viding E (2016) Trajectories of callous-unemotional traits in childhood predict different forms of peer victimization in adolescence. $\mathrm{J}$ Clin Child Adolesc Psychol 28(1):1-9

28. Fontaine NM, McCrory EJ, Boivin M, Moffitt TE, Viding E (2011) Predictors and outcomes of joint trajectories of callousunemotional traits and conduct problems in childhood. J Abnorm Psychol 120(3):730-742

29. Fontaine NM, Rijsdijk FV, McCrory EJ, Viding E (2010) Etiology of different developmental trajectories of callous-unemotional traits. J Am Acad Child Adolesc Psychiatry 49(7):656-664

30. Forsman M, Lichtenstein P, Andershed H, Larsson H (2008) Genetic effects explain the stability of psychopathic personality from mid- to late adolescence. J Abnorm Psychol 117(3):606-617

31. Frick PJ, Hare RD (2001) Antisocial Process Screening Device Toronto. Multi-Health Systems, Canada

32. Frick PJ, Moffitt TE (2010) A proposal to the DSM-V childhood disorders and the ADHD and disruptive behavior disorders work groups to include a specifier to the diagnosis of conduct disorder based on the presence of callous-unemotional traits. American Psychiatric Association, Washington, DC

33. Frick PJ, Ray JV (2015) Evaluating callous-unemotional traits as a personality construct. J Personal 83(6):710-722. doi:10.1111/ jopy. 12114

34. Frick PJ, Ray JV, Thornton LC, Kahn RE (2014) Can callousunemotional traits enhance the understanding, diagnosis, and treatment of serious conduct problems in children and adolescents? A comprehensive review. Psychol Bull 140(1):1-57
35. Gao Y, Glenn AL, Schug RA, Yang Y, Raine A (2009) The neurobiology of psychopathy: a neurodevelopmental perspective. Can J Psychiatry 54(12):813-823

36. Gao Y, Raine A (2010) Successful and unsuccessful psychopaths: a neurobiological model. Behav Sci Law 28:194-210

37. Goodman R (1997) The strengths and difficulties questionnaire: a research note. J Child Psychol Psychiatry 38(5):581-586

38. Hare RD (2003) The Hare psychopathy checklist-revised (PCLR), 2nd edn. Multi-Health Systems, Toronto

39. Hemphill JF, Templeman R, Wong S, Hare RD (1998) Psychopathy and crime: recidivism and criminal careers. In: Cooke DJ, Forth AE, Hare RD (eds) Psychopathy: Theory, research and implications for society. Kluwer, Dordrecht, pp 375-399

40. Hemphälä M, Hodgins S (2014) Do psychopathic traits assessed in mid-adolescence predict mental health, psychosocial, and antisocial, including criminal outcomes, over the subsequent 5 years? Can J Psychiatry 59(1):40-49

41. Herpers PC, Rommelse NN, Bons DM, Buitelaar JK, Scheepers FE (2012) callous-unemotional traits as a cross-disorders construct. Soc Psychiatry Psychiatr Epidemiol 47(12):2045-2064

42. Hicks BM, Vaidyanathan U, Patrick CJ (2010) Validating female psychopathy subtypes: differences in personality, antisocial and violent behavior, substance abuse, trauma, and mental health. Personal Disord 1(1):38-57

43. Humayun S, Kahn RE, Frick PJ, Viding E (2014) Callous-unemotional traits and anxiety in a community sample of 7-yearolds. J Clin Child Adolesc Psychol 43(1):36-42

44. Hunt E, Bornovalova MA, Patrick CJ (2014) Genetic and environmental overlap between borderline personality disorder traits and psychopathy: evidence for promotive effects of factor 2 and protective effects of factor 1. Psychol Med 30:1-11 (epub ahead of print)

45. Isen J, Raine A, Baker LA, Dawson ME, Bezdjian S, Lozano DI (2010) Sex-specific association between psychopathic traits and electrodermal reactivity in children. J Abnorm Psychol 119(1):216-225

46. Keller MC, Medland SE, Duncan LE (2010) Are extended twin family designs worth the trouble? A comparison of the bias, precision, and accuracy of parameters estimated in four twin family models. Behav Genet 40(3):377-393

47. Larsson H, Andershed H, Lichtenstein P (2006) A genetic factor explains most of the variation in the psychopathic personality. $\mathbf{J}$ Abnorm Psychol 115(2):221-230

48. Larsson H, Tuvblad C, Rijsdijk FV, Andershed H, Grann M, Lichtenstein P (2007) A common genetic factor explains the association between psychopathic personality and antisocial behavior. Psychol Med 37(1):15-26

49. Larsson H, Viding E, Plomin R (2008) Callous-unemotional traits and antisocial behavior. Crim Justice Behav 35:197-211

50. Lynam DR (1997) Pursuing the psychopath: capturing the fledgling psychopath in a nomological net. J Abnorm Psychol 106(3):425-438

51. Lynam DR (2002) Fledgling psychopathy: a view from personality theory. Law Hum Behav 26(2):255-259

52. Miller JD, Lynam DR (2015) Psychopathy and personality: advances and debates. J Personal 83(6):585-592. doi:10.1111/ jopy. 12145

53. Murray J, Farrington DP (2010) Risk factors for conduct disorder and delinquency: key findings from longitudinal studies. Can J Psychiatry 55(10):633-642

54. Neale MC, Boker SM, Xie G, Maes H (2003) Mx: statistical modeling, 6th edn. Department of Psychiatry, Medical College of Virginia, Richmond

55. Neale MC, Cardon LR (1992) Methodology for genetic studies of twins and families. Kluwer Academic Publications, Dordrecht 
56. Neumann CS, Hare RD (2008) Psychopathic traits in a large community sample: links to violence, alcohol use, and intelligence. J Consult Clin Psychol 76(5):893-899

57. O’Nions E, Tick B, Rijsdijk F, Happé F, Plomin R, Ronald A, Viding E (2015) Examining the genetic and environmental associations between autistic social and communication deficits and psychopathic callous-unemotional traits. PLoS One 10(9):e0134331

58. Pechorro P, Maroco J, Gonçalves RA, Nunes C, Jesus SN (2014) Psychopathic traits and age of crime onset in male juvenile delinquents. Eur J Criminol 58(12):1412-1414

59. Plomin R, DeFries JC, McClearn GE, McGuffin P (2008) Behavioral genetics, 5th edn. Worth Publisher, United States of America

60. Raftery AE (1995) Bayesian model selection in social research. Sociol Methodol 25:111-163

61. Salekin RT (2016) Psychopathy in childhood: toward better informing the DSM-5 and ICD-11 conduct disorder specifiers. Personal Disord Theory Res Treat 2:180-191

62. Smith SS, Newman JP (1990) Alcohol and drug abuse/dependence disorders in psychopathic and nonpsychopathic criminal offenders. J Abnorm Psychol 99:430-439

63. Somma A, Andershed H, Borroni S, Fossati A (2016) The validity of the child problematic trait inventory in 6-12 year old Italian children: further support and issues of consistency across different sources of information and different samples. J Psychopathol Behav Assess 38(3):350-372

64. Taylor A, Loney BR, Bobadilla L, Iacono WG, McGue M (2003) Genetic and environmental influences on psychopathy trait dimensions in a community sample of male twins. J Abnorm Child Psychol 31(6):633-645

65. Thompson DF, Ramos C, Willett JK (2014) Psychopathy: clinical features, developmental basis and therapeutic challenges. J Clin Pharm Ther 39(5):485-495

66. Tuvblad C (2014) Genetic influences on antisocial behavior over the life course. In: Vaughn MG, DeLisi M (eds) Handbook of biosocial criminology. Routledge, London, pp 77-100

67. Tuvblad C, Baker LA (2011) Human aggression across the lifespan: genetic propensities and environmental moderators. Adv Genet 75:171-214. doi:10.1016/B978-0-12-380858-5.00007-1

68. Tuvblad C, Bezdjian S, Raine A, Baker LA (2013) Psychopathic personality traits and negative parent-to-child affect: a longitudinal cross-lag twin study. J Crim Justice 41(5):331-341
69. Tuvblad C, Bezdjian S, Raine A, Baker LA (2014) The heritability of psychopathic personality in 14 to 15 years old twins, multi-rater and multi-measure approach. Psychol Assess 26(3):704-716

70. Tuvblad C, Wang P, Bezdjian S, Raine A, Baker LA (2015) Psychopathic personality development from ages 9 to 18: genes and environment. Dev Psychopathol 1:27-44

71. Ullrich S, Farrington DP, Coid JW (2008) Psychopathic personality traits and life-success. Personal Individ Differ 44:1162-1171

72. Waldman ID, Rhee S (2006) Genetic and environmental influences on psychopathy and antisocial behavior. In: Patrick CJ (ed) Handbook of psychopathy. Guilford, New York, pp 205-228

73. Wang P, Baker LA, Gao Y, Raine A, Lozano DI (2012) Psychopathic traits and physiological responses to aversive stimuli in children aged 9-11 years. J Abnorm Child Psychol 40(5):759-769

74. Wang P, Gao Y, Isen J, Tuvblad C, Raine A, Baker LA (2015) Genetic covariance between psychopathic traits and anticipatory skin conductance responses to threat: evidence for a potential endophenotype. Dev Psychopathol 27(4 Pt 1):1313-1322

75. Verona E, Vitale J (2006) Psychopathy in women. In: Patrick CJ (ed) Handbook of psychopathy. Guilford Press, NY, pp 415-436

76. Viding E, Blair JR, Moffitt TE, Plomin R (2005) Evidence of substantial genetic risk for psychopathy in 7-year-olds. J Child Psychol Psychiatry 46(6):592-597

77. Viding E, Fontaine NM, McCrory EJ (2012) Antisocial behaviour in children with and without callous-unemotional traits. J R Soc Med 105(5):195-200

78. Viding E, Fontaine NM, Oliver BR, Plomin R (2009) Negative parental discipline, conduct problems and callous-unemotional traits: monozygotic twin differences study. $\mathrm{Br} \mathrm{J}$ Psychiatry 195(5):414-419

79. Viding E, Frick PJ, Plomin R (2007) Aetiology of the relationship between callous-unemotional traits and conduct problems in childhood. Br J Psychiatry 49:33-38

80. Viding E, Jones AP, Frick PJ, Moffitt TE, Plomin R (2008) Heritability of antisocial behaviour at 9: do callous-unemotional traits matter? Dev Sci 11:17-22

81. Viding E, McCrory EJ (2012) Genetic and neurocognitive contributions to the development of psychopathy. Dev Psychopathol 24(3):969-983 